\title{
Determinants of Internet use by the elderly in Spain: Time dedicated to search and communications
}

\author{
Juan Carlos Campaña ${ }^{1, *} \cdot$ Raquel Ortega ${ }^{2}$ \\ ${ }^{1}$ Department of Economics and Business, Antonio de Nebrija University, Madrid, Spain \\ ${ }^{2}$ Department of Business, University of Zaragoza, Zaragoza, Spain
}

Received: 21 November 2019

Revised: 24 April 2020

Accepted: 16 June 2020

\begin{abstract}
Internet use reduces the isolation or exclusion of individuals in specific socio-economic groups and, consequently, increases the quality of life, with this being especially the case for the elderly. Since the elderly are becoming more active in dedicating time to the Internet, we provide evidence of the time that individuals in Spain aged 65 and older dedicate to two online activities: search and communications. Thus, our work contributes to the central objective of the Digital Agenda for Europa, which sets out to ensure universal broadband coverage across the European Union. We estimate a simultaneous SUR model with data from the 4,036 individuals aged 65 years (inclusive) and older from the Spanish Time Use Survey for 20092010. Results indicate that being male has a positive influence on the time devoted to search on the Internet, whereas age has a negative effect. Time devoted to both Internet activities increases with higher levels of education and at the highest level of individual health. By contrast, a larger number of family members has a negative influence on the time spent on search and, more so, on communications. Finally, living in a larger city has a positive effect on the time dedicated to search.
\end{abstract}

Keywords: Elderly; Internet; Time Use; SUR model

JEL Classification Codes: D12, J13, J22

\section{Introduction}

This paper analyzes the socio-demographic determinants of the time that Spanish individuals aged 65 and older spend on two Internet activities: searching for information with the computer, and computer communication. With many millions using the Internet every day around the world, it is essential to recognize the dramatic growth in Internet usage during the last few years for all ages, and the subsequent economic and social implications (Madden and Savage, 2000).

\footnotetext{
*Corresponding author. E-mail: jcampana@nebrija.es.

Citation: Campaña, J. C., and Ortega, R. (2021) Determinants of Internet use by the elderly in Spain: Time dedicated to search and communications, Economics and Business Letters, 10(1), 16-26.
}

DOI: $10.17811 /$ ebl.10.1.2021.16-26 
In addition to the proven fact that the use of the Internet stimulates economic growth (Sassi and Goaied, 2013; Salahuddin and Gow, 2016), it is particularly interesting that Internet use decreases loneliness and depression, improves self-esteem, and consequently increases the quality of life (Shaw and Gant, 2004; Steinfield et al., 2008). This can be particularly the case for the elderly, with the literature suggesting positive effects on psychological well-being (White el al., 1999; Wright, 2000). Specifically, older Internet users are more positive than nonusers in terms of psychological well-being and personal characteristics (Chen and Persson, 2002). Shapira et al. (2007) show that computer and Internet use seems to contribute to older adults' well-being and sense of empowerment by affecting their interpersonal interactions, promoting their cognitive functioning, and contributing to their experience of control and independence. Additionally, White et al. (2002) show that older adults appear to gain from Internet use in several ways, including self-efficacy, mastery, and empowerment. Eastman and Iyer, (2005) discuss the impact of the cognitive age of American consumers aged 65 or older on their Internet use, with results indicating that seniors with lower cognitive age will use the Internet more than seniors who are older in cognitive age.

Despite all this positive evidence regarding internet use and older adults, to the best of our knowledge, very few prior papers have addressed the impact of socio-demographic variables on the different uses of the Internet by the elderly population. National evidence on the determinants of the elderly's use of the Internet has been provided for the US, in a sample of 2,284 individuals from the 2004 wave of the Health and Retirement Study (Hogeboom et al., 2010). For the New England region, with a sample of 198 older adults, the breadth of ICT use, technology experience, and socio-personal characteristics (Vroman et al., 2015) have all been analyzed, while other empirical evidence is based on a sample of 58 older individuals in the US (Gatto and Tak, 2008), and on a very small sample of 22 older people surveyed in Israel (Shapira et al., 2007). Against this background, the main objective of this paper is to analyze how sociodemographic characteristics influence the time spent by older Spanish adults on internet activities. We analyze the time that 4,036 individuals aged 65 (inclusive) devote to two principal activities: searching for information with the computer and computer communication. To that end, we use data from the Spanish Time Use Survey-STUS for 2009-2010 and we estimate a linear seemingly unrelated regressions (SUR) simultaneous model for these two uses of time.

Our results indicate that being male has a positive influence on the time devoted to searching for information with the computer, whereas age has a negative effect on this activity. Time devoted to both activities increases at the highest level of education, and health status shows a significant and positive influence. Furthermore, a larger number of family members has a negative influence on the time spent on search and, more so, on computer communications. Thus, our evidence shows that older adults interact online, according to certain socio-demographic variables. This will be useful to policy-makers who wish to assess the recently-proven "beneficial" use of online activities, by devising policy instruments to increase the at-home demand for online activities, in order to contribute to the central objective of the Digital Agenda for Europe, which sets out to ensure universal broadband coverage across the European Union.

\section{Framework}

The Internet affects the way people communicate and interact, a phenomenon that may influence social network characteristics (Coget et al., 2002; Katz \& Rice, 2002; Bargh \& McKenna, 2004). Authors such as Wellman et al. (2001), Kraut et al. (2002), and Boase et al. (2006) suggest that Internet use may strengthen social networks, which may be of special significance for older adults, for whom social networks may be diminishing (Pillemer and Glasgow, 2000; Alpass \& Neville, 2003; Havens et al., 2004). An increasing number of older adults are using 
computers for communication, entertainment, and information (Gatto and Tak, 2008). Furthermore, the older adult age group is becoming one of the fastest growing online user groups (Fox, 2004; Nahm et al., 2004).

The literature suggests that Internet tools such as e-mail for communication, using computers for entertainment, and the internet for information helps older adults feel less isolated and lonely (Malcolm et al., 2001; Nahm \& Resnick, 2001; Clark, 2002; Fogel et al., 2003). In this sense, older adults are using computer technology for communicating with family and friends via email, enjoying computer software for entertainment, and searching Internet Web sites for information on personal issues and health (Gatto and Tak, 2008; Vronam et al, 2015). With respect to internet activities, E-mail is the favorite computer activity for the older age group (Nahm, 2003; Fox, 2004; Hilt \& Lipschultz, 2004; Saunder, 2004; Mann et al., 2005), while finding information on the computer is also a primary activity of older Internet and computer users (Saunder, 2004; Mann et al., 2005; Tak \& Hong, 2005).

Table 1, using data provided by the Media General Study (Estudio General de Medios, 2016), allows us to see changes and trends in the use of the Internet in Spain over a period of 10 years (2006-2016). We can see that the number of Spaniards who use the Internet has increased more than 300 percent in this period $(8,317,000$ individuals in 2006, compared to $28,231,000$ individuals in 2016). As can be seen in Table 1, the use of the internet by men in 2006 was greater $(58.40 \%)$ than by women $(41.60 \%)$, but this difference has decreased over the years since then. In $2016,50.05 \%$ of men and $49.95 \%$ of women used the internet. Our study sample (individuals aged 65 and older) shows considerable growth in Internet use, from 5.3\% in 2008 to $10 \%$ in 2016.

\section{Data}

We use the last time use survey from Spain (2009-2010), restricting our sample to the 4,036 individuals aged 65 years (inclusive) and older, and we focus on analysing the time dedicated by those surveyed to two principal activities: searching for information with the computer, and computer communication. In these surveys, each interviewee fills in a diary for a specific day of the week, indicating what activities were done during the course of the day, in intervals of 10 minutes, for a total of 144 intervals. Time-use surveys provide information on time use per

Table 1. Internet users in Spain.

\begin{tabular}{|c|c|c|c|c|c|c|c|c|c|c|c|}
\hline Years & 2006 & 2007 & 2008 & 2009 & 2010 & 2011 & 2012 & 2013 & 2014 & 2015 & 2016 \\
\hline Users & 8,317 & 9,944 & 11,443 & 13,525 & 15,127 & 16,768 & 18,437 & 21,116 & 24,076 & 26,496 & 28,231 \\
\hline \multicolumn{12}{|l|}{ Gender } \\
\hline Male & 58.40 & 58.00 & 56.60 & 55.20 & 56.10 & 55.20 & 54.30 & 52.60 & 51.30 & 50.47 & 50.05 \\
\hline Female & 41.60 & 42.00 & 43.40 & 44.80 & 43.90 & 44.80 & 45.70 & 47.40 & 48.70 & 49.53 & 49.95 \\
\hline \multicolumn{12}{|l|}{ Age } \\
\hline $14-19$ & 15.3 & 14.9 & 12.3 & 11.9 & 11.1 & 10.7 & 10.5 & 10.0 & 9.3 & 8.7 & 8.4 \\
\hline $20-24$ & 15.0 & 13.4 & 11.0 & 11.3 & 11.0 & 10.2 & 9.8 & 9.1 & 8.6 & 8.0 & 7.3 \\
\hline $25-34$ & 30.3 & 28.6 & 27.6 & 28.1 & 27.0 & 26.1 & 25.3 & 23.5 & 21.6 & 19.5 & 18.3 \\
\hline $35-44$ & 20.6 & 22.2 & 22.0 & 22.2 & 23.5 & 23.8 & 24.3 & 24.7 & 25.0 & 24.6 & 23.9 \\
\hline $45-54$ & 12.3 & 13.6 & 14.3 & 14.0 & 14.6 & 15.1 & 15.4 & 16.1 & 17.3 & 18.8 & 19.6 \\
\hline $55-64$ & 5.0 & 5.7 & 7.4 & 7.3 & 7.5 & 8.1 & 8.4 & 9.0 & 10.0 & 11.1 & 12.7 \\
\hline Since 65 & - & - & 5.3 & 5.2 & 5.4 & 5.9 & 6.4 & 7.6 & 8.1 & 9.2 & 10.0 \\
\hline
\end{tabular}

Note: Own elaboration based on the Internet audience in the General Media Study (EGM) from Spain http://www.aimc.es/-Audiencia-de-Internet-en-el-EGM-.html. Users individuals in thousands (Base: users yesterday). Gender individuals in percentages (Base: users yesterday). Age individuals in percentages (Base: users yesterday). The value for 2015 corresponds to the mean of the waves of the months of February/March, April/May and October/November. The value for 2016 corresponds to the mean of the waves of the months of February/March and April/May. 
individual and are the typical instrument used to analyse time-allocation decisions (Aguiar and Hurst 2007; Giménez-Nadal and Sevilla 2012). Furthermore, an extensive literature confirms the validity and reliability of data from diaries and its advantages over other time-use surveys based on simple questions, in which those being surveyed are asked to estimate the time dedicated to a certain activity on a "typical day" or during a "typical week"; for example, the hours that the surveyed individual has worked the day or the week before (Bianchi et al. 2006; Kalenkoski and Pabilonia 2012).

\section{Methodology}

Hamermesh and Lee (2007) argue that time is scarce and individuals suffer from lack of sufficient time to carry out all desired activities, and we know that men and women have different preferences at different stages of their lives (Molina et al., 2017). Each individual reports two uses of time and, as in other time-use studies (Giménez-Nadal and Molina 2013, 2015; Molina et al., 2016; Campaña et al., 2017), we estimate a SUR (seemingly unrelated regressions) simultaneous model for the time that men and women spend in both search and in computer communication.

The statistical model is as follows: For an individual " $i$ ", $T_{s i}$ and $T_{c i}$, represent the hours reported by those individuals dedicated to search and to communication, respectively. $\mathrm{X}_{\mathrm{i}}$ is the vector of the characteristics of the household and of the individuals, and $\varepsilon_{\mathrm{si}}$ and $\varepsilon_{\mathrm{ci}}$, represent the random variables for unmeasured factors. Thus, we estimate the following two equations:

$$
\begin{aligned}
& T_{s i}=\beta \mathrm{X}_{\mathrm{i}}+\varepsilon_{\mathrm{si}} \\
& T_{c i}=\beta \mathrm{X}_{\mathrm{i}}+\varepsilon_{\mathrm{ci}}
\end{aligned}
$$

Concerning the specification of the error terms for each individual, we permit the correlations in the unobserved determinants of the activities, and the error terms are normally distributed as a whole, without restrictions in the correlation. This specification shows the time limitation that could lead individuals to spend more time on one activity, and less time on another. Moreover, we assume that the error components are independent:

$$
\left[\begin{array}{c}
\varepsilon_{\mathrm{si}} \\
\varepsilon_{\mathrm{ci}}
\end{array}\right] \sim \mathrm{N}\left(\left[\begin{array}{lll}
0 & \sigma_{\mathrm{si}}^{2} & \rho_{\mathrm{sici}} \sigma_{\mathrm{si}} \sigma_{\mathrm{ci}} \\
0 & \rho_{\mathrm{cisi}} \sigma_{\mathrm{ci}} \sigma_{\mathrm{si}} & \sigma_{\mathrm{ci}}^{2}
\end{array}\right)\right.
$$

$\mathrm{Xi}$ includes the following variables, age and age squared divided by 100 (Kalenkoski et al., 2005; Aguiar and Hurst 2007; Giménez-Nadal et al., 2011), in order to take into account the allocation of time to an activity over the whole life cycle. The gender variable is important in that free time preferences vary with gender (Giménez Nadal and Sevilla 2012). We control for three levels of education, as in Campaña et al., (2018), Primary education (less than a secondary school diploma), Secondary education (a secondary school diploma), and University education (more than a secondary school diploma). Education influences the distribution of time that individuals allocate to different activities (Kalenkoski et al., 2005; Guryan et al. 2008; GiménezNadal \& Molina, 2013; Campaña et al., 2017).

We consider whether the individuals surveyed are living together in couple, since this can influence the time dedicated to these activities. Studies such as Giménez-Nadal and Molina (2015) show that an individual's good health can lead to the individual dedicating more time to 
market work and less time to leisure activities, so we control for the state of health of the individual (self-reported) with five levels ( $1=$ very good health, to $5=$ very poor health). The number of household members is also included, and we consider the size of the municipality where the interviewee lives, with five classifications: municipality with a population greater than 100,000 , municipality with a population of between 50,000 and 100,000 , municipality with a population of between 20,000 and 50,000, municipality with a population of between 10,000 and 20,000, and municipality with a population of less than 10,000 (Molina et al., 2016).

Table 2 shows the descriptive statistics for the average time that those interviewed dedicated, in hours per day, to search and communication, as well as the descriptive statistics for our sociodemographic variables; Column 1 for men, Column 2 for women, and Column 3 for the whole sample. With respect to the time dedicated to search, men devote more time (0.06 hours per day) than do women ( 0.01 hours per day) to this activity, with this being similar to the time spent by men ( 0.02 hours per day) and women ( 0.01 hours per day) in communication. The average age is 74.39 years for men and 75.20 years for women. Concerning education levels, the majority of the individuals have had a primary education (85\%). We observe also that $80 \%$ of men and $48 \%$ of women live with a partner. As for their state of health, $37 \%$ of the men report being in good health, while $36 \%$ of the women report being in acceptable health. With regard to household characteristics, there is an average of more than two inhabitants per household. Furthermore, $44 \%$ of the men and women included in our study live in a municipality with a population of more than 100,000 .

Table 2. Descriptive statistics.

\begin{tabular}{lrrrrrrr}
\hline & \multicolumn{3}{c}{ Men } & \multicolumn{2}{c}{ Women } & \multicolumn{2}{c}{ Total } \\
\cline { 2 - 7 } Variables & Mean & SD & Mean & SD & \multicolumn{1}{c}{ Mean } & SD \\
\hline \hline Search (daily hours) & 0.06 & $(0.353)$ & 0.01 & $(0.160)$ & 0.03 & $(0.262)$ \\
Computer comunication (daily hours) & 0.02 & $(0.185)$ & 0.01 & $(0.132)$ & 0.02 & $(0.157)$ \\
Age & 74.39 & $(6.823)$ & 75.20 & $(7.052)$ & 74.85 & $(6.965)$ \\
Primary education & 0.81 & $(0.394)$ & 0.89 & $(0.312)$ & 0.85 & $(0.352)$ \\
Secondary education & 0.10 & $(0.302)$ & 0.06 & $(0.241)$ & 0.08 & $(0.269)$ \\
University education & 0.09 & $(0.288)$ & 0.05 & $(0.213)$ & 0.07 & $(0.249)$ \\
Living as a couple & 0.80 & $(0.397)$ & 0.48 & $(0.500)$ & 0.62 & $(0.486)$ \\
Very good health & 0.06 & $(0.229)$ & 0.05 & $(0.211)$ & 0.05 & $(0.219)$ \\
Good health & 0.37 & $(0.483)$ & 0.29 & $(0.456)$ & 0.33 & $(0.469)$ \\
Acceptable health & 0.35 & $(0.478)$ & 0.36 & $(0.479)$ & 0.35 & $(0.478)$ \\
Poor health & 0.18 & $(0.386)$ & 0.24 & $(0.427)$ & 0.21 & $(0.411)$ \\
Very poor health & 0.04 & $(0.201)$ & 0.07 & $(0.247)$ & 0.06 & $(0.229)$ \\
No. household members & 2.35 & $(1.032)$ & 2.12 & $(1.137)$ & 2.22 & $(1.099)$ \\
Municipality size 1 & 0.42 & $(0.494)$ & 0.46 & $(0.499)$ & 0.44 & $(0.497)$ \\
Municipality size 2 & 0.09 & $(0.292)$ & 0.09 & $(0.282)$ & 0.09 & $(0.286)$ \\
Municipality size 3 & 0.11 & $(0.312)$ & 0.09 & $(0.289)$ & 0.10 & $(0.299)$ \\
Municipality size 4 & 0.10 & $(0.295)$ & 0.09 & $(0.286)$ & 0.09 & $(0.290)$ \\
Municipality size 5 & 0.28 & $(0.450)$ & 0.27 & $(0.444)$ & 0.28 & $(0.447)$ \\
Observations & & 1734 & & 2302 & & 4036 \\
\hline \hline
\end{tabular}

Note: Standard deviations in parentheses. Data from the Spanish TUS 2009-2010. The sample is restricted to individuals aged 65 and older. Primary education is equivalent to having less than a secondary school diploma. Secondary education is equivalent to having a secondary school diploma. University education is equivalent to having more than a secondary school diploma. Municipality size 1 is equivalent to a municipality with a population greater than 100,000 , municipality size 2 is equivalent to a municipality with a population between 50,000 and 100,000 , municipality size 3 is equivalent to a municipality with a population between 20,000 and 50,000, municipality size 4 is equivalent to a municipality with a population between 10,000 and 20,000, and municipality size 5 is equivalent to a municipality with a population less than 10,000 . 
Table 3. Estimations of the SUR model.

\begin{tabular}{|c|c|c|}
\hline \multirow[b]{2}{*}{$\begin{array}{l}\text { Variables } \\
\text { (Adults since age 65) }\end{array}$} & $\overline{(1)}$ & $\overline{(2)}$ \\
\hline & Search & $\begin{array}{r}\text { Computer communica- } \\
\text { tion }\end{array}$ \\
\hline \multirow[t]{2}{*}{ Male } & $0.0360 * * *$ & 0.00274 \\
\hline & $(0.00833)$ & $(0.00513)$ \\
\hline \multirow[t]{2}{*}{ Age } & $-0.0154 *$ & -0.00719 \\
\hline & $(0.00914)$ & $(0.00763)$ \\
\hline \multirow[t]{2}{*}{ Age squared } & 0.00857 & 0.00431 \\
\hline & $(0.00571)$ & $(0.00501)$ \\
\hline \multirow[t]{2}{*}{ High school degree } & $0.0644 * *$ & $0.0301 * *$ \\
\hline & $(0.0254)$ & $(0.0120)$ \\
\hline \multirow[t]{2}{*}{ Some college } & $0.0934 * * *$ & $0.104 * * *$ \\
\hline & $(0.0304)$ & $(0.0263)$ \\
\hline \multirow[t]{2}{*}{ Living as a couple } & 0.0102 & 0.00203 \\
\hline & $(0.00667)$ & $(0.00467)$ \\
\hline \multirow[t]{2}{*}{ Very good health } & $0.0682 *$ & $0.0437 *$ \\
\hline & $(0.0357)$ & $(0.0246)$ \\
\hline \multirow[t]{2}{*}{ Good health } & 0.00116 & 0.00399 \\
\hline & $(0.0168)$ & $(0.00786)$ \\
\hline \multirow[t]{2}{*}{ Acceptable health } & -0.0140 & -0.00216 \\
\hline & $(0.0153)$ & $(0.00691)$ \\
\hline \multirow[t]{2}{*}{ Bad health } & -0.00660 & -0.00394 \\
\hline & $(0.0157)$ & $(0.00662)$ \\
\hline \multirow[t]{2}{*}{ No. household members } & $-0.00430 *$ & $-0.00400 * * *$ \\
\hline & $(0.00253)$ & $(0.00149)$ \\
\hline \multirow[t]{2}{*}{ Municipality size 1} & $0.0299 * * *$ & -0.00228 \\
\hline & $(0.00789)$ & $(0.00537)$ \\
\hline \multirow[t]{2}{*}{ Municipality size 2} & 0.000389 & 0.00816 \\
\hline & $(0.0148)$ & $(0.0116)$ \\
\hline \multirow[t]{2}{*}{ Municipality size 3} & $-0.0128 * *$ & 0.00844 \\
\hline & $(0.00563)$ & $(0.00943)$ \\
\hline \multirow[t]{2}{*}{ Municipality size 4} & 0.0180 & 0.00557 \\
\hline & $(0.0147)$ & $(0.00927)$ \\
\hline \multirow[t]{2}{*}{ Constant } & $0.658 *$ & 0.296 \\
\hline & $(0.366)$ & $(0.291)$ \\
\hline R-squared & 0.042 & 0.044 \\
\hline Observations & 4,036 & 4,036 \\
\hline
\end{tabular}

Note: Robust standard errors in parentheses. Data from the Spanish TUS 2009-2010. The sample is restricted to individuals aged 65 and older. Primary education is equivalent to having less than a secondary school diploma. Secondary education is equivalent to having a secondary school diploma. University education is equivalent to having more than a secondary school diploma. Municipality size 1 is equivalent to a municipality with a population greater than 100,000 , municipality size 2 is equivalent to a municipality with a population between 50,000 and 100,000, municipality size 3 is equivalent to a municipality with a population between 20,000 and 50,000, municipality size 4 is equivalent to a municipality with a population between 10,000 and 20,000, and municipality size 5 is equivalent to a municipality with a population less than 10,000 . Sunday taken as a reference day. * Significant at $90 \%$. ** Significant at $95 \%$. *** Significant at $99 \%$.

\section{Results}

Columns 1 and 2 of Table 3 show the results of our SUR estimations for the time dedicated to search and communication in Spain. Gender influences the time spent on search, in that being a man generates a positive influence on the time devoted to search. Prior research shows that 
there are gender differences in the time spent by individuals on certain internet activities (Molina et al., 2017). In terms of age, we found, as expected, a negative effect on the time dedicated to search (Madden and Savage, 2000; Chen and Persson, 2002; Wright and Hill, 2009; Hoogeboom et al 2010; Vroman et al.,2015). With respect to education, we find that the time devoted to search and communication increases at higher levels of education. Regarding terms of education, these results are similar to those presented by Hoogeboom et al (2010) and Vroman et al. (2015).

Health status shows a significant influence on the time dedicated to search and communication, in that individuals with better health spend more time in these activities. A good health status influences positively the time spent by individuals on internet activities (Molina et al. 2017). Furthermore, this is in line with Wright and Hill (2009), who show that being disabled specifically, having a limited physical mobility - and being restricted to the house, have negative impacts on computer use.

As for the number of household members, a larger number of household members influences individuals to spend less time on both search and communication. With respect to the size of the municipality, we see significant and positive values for municipality size 1 (municipality with a population greater than 100,000) and significant and negative values for municipality size 3 (a municipality with a population between 20,000 and 50,000) in the time devoted to search. Thus, living in larger cities produces a positive effect on the time dedicated to this activity, with this evidence being in line with the related literature (Kelly and Lewis, 2001).

\section{Discussion}

It is clear that, while increasing the access of the elderly to the use of online resources, policymakers must bear in mind the need to act to protect this vulnerable elderly segment. In this context, we provide evidence of the socio-demographic determinants of the time the elderly dedicate to two online activities: search and communications. To that end, we estimate a simultaneous SUR model with data from the Spanish Time Use Survey for 2009-2010.

Our results indicate that being male has a positive influence on the time devoted to search, and that age has a negative effect. Time devoted to search and communication increases at the highest level of education. Health status shows a significant and positive influence on the time dedicated to both activities. A larger number of household members influences individuals to spend less time on search and communication and, with respect to the size of the municipality, living in larger cities has a positive effect on the time dedicated to looking for information. These results are in line with those obtained in prior research (Madden and Savage, 2000; Kelly and Lewis, 2001; Chen and Persson, 2002; Wright and Hill, 2009; Hoogeboom et al 2010; Vroman et al.,2015; Molina et al 2017).

In the context of public policy, certain recommendations can be derived from our empirical results for the case of Spain. The fact that a larger number of household members influences negatively the time spent by the elderly in these two internet activities could indicate to policy makers that these older adults would need support from outside their home, to devote more time on these two internet activities. Thus, computer training, development of Internet-accessible educational materials, and online social support are among the interventions that can benefit older adults, who can learn to use computers and Internet surfing more effectively with adequate training (Dauz et al., 2004), and their level of confidence and ease of use of the technology increases with practice. (Adams et al., 2005). 


\section{Limitation}

One limitation of our study is that, although the STUS contains time use information for all family members older than 9 years of age, we cannot account for unobserved heterogeneity in preferences for household production or leisure, since the STUS does not have a panel data structure.

\section{Conclusions}

It is a fact that the Internet has become an integral part of the daily life of the elderly, and the World Wide Web has attracted, and continues to attract, more and more older individuals. Exploring the determinants of Internet use is important in designing policies to improve the provision of online services for the elderly. We provide evidence that contributes to the central objective of the Digital Agenda for Europe, which sets out to ensure universal broadband coverage across the European Union. Thus, it is critical to stimulate the elaboration of further studies that will provide information about European (and other) countries that will assist in understanding the interactions with the Internet of the elderly, one of the fastest-growing online user groups.

\section{Disclosure statement}

No potential conflict of interest was reported by the authors.

\section{References}

Adams, N., Stubbs, D., and Woods, V. (2005) Psychological barriers to Internet usage among older adults in the UK, Medical Informatics and the Internet in Medicine, 30, 3-17.

Aguiar, M., and Hurst, E. (2007) Measuring trends in leisure: the allocation of time over five decades, Quarterly Journal of Economics, 115, 969-1006.

Alpass, F. M., and Neville, S. (2003) Loneliness, health and depression in older males, Aging \& Mental Health, 7, 212-216.

Bargh, J. A., and Mckenna, K. Y. A. (2004) The internet and social life, Annual Review of Psychology, 55, 573-590

Bianchi, S. M., Robinson, J. P., and Milkie, M. A. (2006) Changing Rhythms of American Family Life, Russell Sage, New York.

Boase, J., Horrigan, J. B., Wellman, B., and Rainie, L. (2006) The strength of internet ties, Washington, DC: Pew Internet and American Life Project. Retrieved September 8, 2008, from http://www.pewinternet.org/pdfs/PIP_Internet_ties.pdf

Campaña, J., Giménez, J. I., and Molina, J. A. (2017) Increasing the human capital of children in Latin America: The role of parent's time into childcare, Journal of Development Studies.

Campaña, J. C., Giménez-Nadal, J. I., and Molina, J. A. (2018) Gender norms and the gendered distribution of total work in Latin American households, Feminist Economics, 24(1), 35-62.

Chen, Y., and Persson, A. (2002) Internet use among young and older adults: relation to psychological well-being, Educational Gerentology, 28, 731-744.

Clark, D. J. (2002) Older adults living through and with their computers, CIN: Computers, Informatics, Nursing, 20(3), 117-124.

Coget, J., Yamauchi, Y., and Suman, M. (2002) The internet, social networks, and loneliness, IT \& Society, 1, 180-201 
Dauz, E., Moore, J., Smith, C. E., Puno, F., and Schaag, H. (2004) Installing computers in older adults' homes and teaching them to access a patient education web site: A systematic approach, CIN: Computers, Informatics, Nursing, 22(5), 266-272.

Eastman, J. K., and Iyer, R. (2005) The impact of cognitive age on Internet use of the Elderly: an introduction to the public policy implications, International Journal of Consumer Studies, 29 (2), 125-136.

Fogel, J., Albert, S. M., Schnabel, F. Ditkoff, B. A., and Neugut, A. I. (2003) Racial=ethical differences and potential psychological benefits in use of the Internet by women with breast cancer, Psycho-Oncology, 12, 107-117

Fox, S. (2004) Older Americans and the Internet. Retrieved January 5, 2007, from http://www.pewinternet.org/pdfs/PIP_Seniors_Online_2004.pdf

Gatto, S. L., and Tak, S. H. (2008) Computer, Internet, and e-mail use among older adults: Benefits and Barriers, Educational Gerontology, 34, 800-811.

Giménez-Nadal, J. I., and Molina, J. A. (2013) Parents' education as a determinant of educational childcare time, Journal of Population Economics,26(2), 719-749.

Giménez-Nadal, J. I., and Molina, J. A. (2015) Health status and the allocation of time: Crosscountry evidence from Europe, Economic Modelling, 46, 188-203

Giménez-Nadal, J. I., and Sevilla, A. (2012) Trends in time allocation: a cross-country analysis, European Economic Review, 56, 1338-59.

Giménez-Nadal, J. I., Molina, J. A., and Ortega, R. (2011) Self-employed mothers and the work-family conflict, Applied Economics, 44(17), 2133-2147.

Guryan, J., Hurst, E, and Kearney, M. (2008) Parental education and parental time with children, Journal of Economic Perspectives, 22, 23-46

Hamermesh, D. S., and Lee, J. (2007) Stressed out on four continents: Time crunch or yuppie kvetch?, The Review of Economics and Statistics, 89(2), 374-383.

Havens, B., Hall, M., Sylvestre, G., and Jivan, T. (2004) Social isolation and loneliness: Differences between older rural and urban Manitobans. Canadian Journal on Aging, 23, 129140.

Hilt, M., and Lipschultz, J. H. (2004) Elderly Americans and the Internet: E-mail, TV news, information and entertainment websites, Educational Gerontology, 30, 57-72.

Hogeboom, D. L., Mc Dermott, R. J., Perrin, K. M., and Osman, H. (2010) Internet use and social networking among middle age and older adults, Educational Gerontololy, 36, 93-111.

Kalenkoski, C. M., and Pabilonia, S. W. (2012) Time to work or time to play: the effect of student employment on homework, sleep, and screen time, Labour Economics, 19, 211-21.

Kalenkoski, C., Ribar, D., and Stratton, L. (2005) Parental child care in single parent, cohabiting, and married couple families: time diary evidence from the United Kingdom, American Economic Review: Papers and Proceedings, 95, 194-8.

Katz, J. E., and Rice, R. E. (2002) America and the internet: Access, involvement, and social interaction, in Social consequences of internet use: Access, involvement, and interaction. Cambridge, MA: The MIT Press.

Kelly, R. E. and Lewis, P. E. T. (2001) Household demand for Internet connection, The Journal of Media Economics, 14(4), 249-265.

Kraut, R., Kiesler, S., Boneva, B., Cummings, J., Helgeson, V., and Crawford, A. (2002) Internet paradox resvisited, Journal of Social Issues, 58, 49-74.

Madden, G., and Savage, S. J. (2000) Some economic and social aspects of residential Internet use in Australia, The Journal of Media Economics, 13 (3), 171-185.

Mann, W. C., Belchior, P. R., Kemp, T. and Kemp, B. J. (2005) Computer use by middle aged and older adults with disabilities, Technology and Disability, 17, 1-9. 
Media General Study-Estudio General de Medios (2016) Available via http://www.aimc.es/Audiencia-de-Internet-en-el-EGM-.html.

Molina, J. A., Campaña, J. C., and Ortega, R. (2016) What do you prefer for a relaxing time at home: reading, watching TV or listening to the radio?, Applied Economics Letters, 23 (18), 1278-1284.

Molina, J. A., Campaña, J. C., and Ortega, R. (2017) Children's interaction with the Internet: time dedicated to communications and games, Applied Economics Letters, 24(6), 359-364.

Nahm, E. S. (2003) A model of computer-mediated social support among older adults, unpublished doctoral dissertation, Baltimore, Maryland, University of Maryland.

Nahm, E. S. and Resnick, B. (2001) Homebound older adult's experiences with the Internet and e-mail, Computers in Nursing, 19(6), 257-263.

Nahm, E. S., Resnick, B., and Gains, J. (2004) Testing the reliability and validity of computermediated social support measures among older adults, Computers, Informatics, Nursing, 22, 211-219.

Pillemer, K., and Glasgow, N. (2000) Social integreation and aging: Background and trends, in K. Pillemer, P. Moen, E. Wethington, and N. Glasgow (Eds.), Social integration in the second half of life. Baltimore: The John Hopkins University Press.

Salahuddin, M., and Gow, J. (2016) The effects of Internet usage, financial development and trade openness on economic growth in South Africa: A time series analysis, Telematics and Informatics, 33(4), 1141-1154.

Sassi, S., and Goaied, M. (2013) Financial development, ICT diffusion and economic growth: Lessons from MENA region, Telecommunications Policy 37, 252-261.

Saunder, E. J. (2004) Maximizing computer use among the elderly in rural senior centers. Educational Gerontology, 30, 573-585

Shapira, N., Barak, A., and Gal, I. (2007) Promoting older adults' well-being through Internet training and use, Ageing \& Mental Health, 11 (5), 477-484.

Shaw, L. H., and Gant, L. M. (2004) In defense of the Internet: The relationship between Internet communication and depression, loneliness, self-esteem, and perceived social support, Journal of Obstetrics and Gynaecology Canada, 41(10).

Steinfield, C., Ellison, N. B., and Lampe, C. (2008) Social capital, self-esteem, and use of online social network sites: A longitudinal analysis, Journal of Applied Developmental Psychology, 29(6), 434-445.

Tak, S. H. and Hong, S. H. (2005) Use of the Internet for health information by older adults with arthritis, Orthopaedic Nursing, 24(2), 134-138

Vroman, K. G., Arthanat, S., and Lysack, C. (2015) "Who over 65 is online?" Older adults' dispositions toward information communication technology, Computers in Human Behavior, 43, 156-166.

Wellman, B., Haase, A. Q., Witte, J., and Hampton, K. (2001) Does the internet increase, decrease, or supplement social capital, American Behavioral Scientist, 45, 436-455.

White, H., McConnell, E., Clipp, E., Branch, L.G., Sloane, R., Pieper, C., and Box, T.L. (2002) A randomized controlled trial of the psychosocial impact of providing Internet training and access to older adults, Ageing \& Mental Health, 6(3), 213-221.

White, H., McConnell, E., Clipp, E., Bynum, L., Teague, C., Navas, L., et al. (1999) Surfing the net in later life: A review of the literature and pilot study of computer use and quality of life, Journal of Applied Gerontology, 18, 358-378.

Wright, K. (2000) Computer-mediated social support, older adults, and coping, Journal of Communication, 50(3), 100-118. 
Wright, D. W., and Hill, T. J. (2009) Prescription for trouble: Medicare Part D and patterns of computer and Internet access among the elderly, Journal of Aging and Social Policy, 21, 172186. 